\title{
An Update on Psychopharmacological Treatment of Autism Spectrum Disorder
}

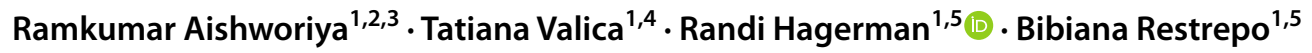

Accepted: 3 January 2022 / Published online: 14 January 2022

(c) The Author(s) 2022

\begin{abstract}
While behavioral interventions remain the mainstay of treatment of autism spectrum disorder (ASD), several potential targeted treatments addressing the underlying neurophysiology of ASD have emerged in the last few years. These are promising for the potential to, in future, become part of the mainstay treatment in addressing the core symptoms of ASD. Although it is likely that the development of future targeted treatments will be influenced by the underlying heterogeneity in etiology, associated genetic mechanisms influencing ASD are likely to be the first targets of treatments and even gene therapy in the future for ASD. In this article, we provide a review of current psychopharmacological treatment in ASD including those used to address common comorbidities of the condition and upcoming new targeted approaches in autism management. Medications including metformin, arbaclofen, cannabidiol, oxytocin, bumetanide, lovastatin, trofinetide, and dietary supplements including sulforophane and $\mathrm{N}$-acetylcysteine are discussed. Commonly used medications to address the comorbidities associated with ASD including atypical antipsychotics, serotoninergic agents, alpha-2 agonists, and stimulant medications are also reviewed. Targeted treatments in Fragile X syndrome (FXS), the most common genetic disorder leading to ASD, provide a model for new treatments that may be helpful for other forms of ASD.
\end{abstract}

Keywords Autism spectrum disorder $\cdot$ Autism $\cdot$ Pharmacology $\cdot$ Medications

\section{Introduction}

ASD is a complex neurodevelopmental, biologically based condition with an estimated prevalence of 1 in 44 people [1] that impacts all areas of child development — from behavior, problem solving abilities and self-care skills, to complex

Randi Hagerman

rjhagerman@ucdavis.edu

1 Medical Investigation of Neurodevelopmental Disorders (MIND) Institute, University of California Davis, 2825 50th Street, Sacramento, CA 95817, USA

2 Khoo Teck Puat-National University Children's Medical Institute, National University Health System, 5 Lower Kent Ridge Road, Singapore 119074, Singapore

3 Department of Pediatrics, Yong Loo Lin School of Medicine, National University of Singapore, 1E Kent Ridge Road, Singapore 119228, Singapore

4 Association for Children With Autism, Chisinau, Moldova

5 Department of Pediatrics, University of California Davis School of Medicine, 4610 X St, Sacramento, CA 95817, USA social communication ability, language, and executive functioning skills. The range of symptoms and severity of ASD vary greatly from child to child, and clinical manifestations depend on the individual's age, cognitive and language abilities, and co-occurring conditions. The last revision of the Diagnostic and Statistical Manual (DSM-5) defines ASD as impairments in two main domains: (1) social communication and interaction, which comprises challenges in social-emotional reciprocity, challenges in using nonverbal strategies during social interaction, and challenges developing, maintaining and understanding relationships, and (2) restricted, repetitive, and stereotyped patterns of behavior, manifested by unusual repetitive movements or behaviors, restricted interests, insistence on sameness and inflexible adherence to routines, as well as sensory challenges ranging from seeking to avoiding certain sensory stimuli [2-4]. However, a range of behavioral, cognitive, and emotional disturbances in ASD can also be attributed to a high rate of co-occurring mental health and medical conditions such as attention deficit hyperactivity disorder (ADHD), anxiety, depression, phobias, intellectual disability, speech/language impairment, restrictive/avoidant food intake, sleep issues, 
sensory processing issues, and genetic conditions. This often makes the recognition, diagnosis, and clinical management of ASD even more complex and difficult [5-8].

Classic medical management of medical conditions has largely revolved around pharmacological treatment. However, despite decades of research in ASD, current evidence has only established behavioral (non-pharmacological) treatments as the mainstay of management to address the core symptoms of ASD. Part of the reason for a lack of efficacy in many treatment studies stems from the heterogeneous etiology underlying the overall term of ASD. Some studies have subdivided enrolled patients either by their genetic etiology or phenotypic features to address this. The aim of this paper is to provide a current update on the pharmacological treatments available for ASD and therapeutic subtypes of ASD, covering both the established ones and upcoming/ emerging treatments which have potential based on scientific evidence to become standard treatments in the next few years. A systematic literature search was completed on Medline, Scopus, and Embase with key search terms of "autism," "autism spectrum disorder," "targeted treatments," "pharmacological therapy," and "management" to identify relevant articles. Here we have highlighted the psychopharmacological treatments that have the most efficacy and are also, in most cases, available now or in the near future to clinicians. However, we also recognize the current mainstay of behavioral intervention in the management of ASD and will briefly review those which are supported by strong empirical evidence.

\section{Non-pharmacological (Behavioral) Interventions}

In 1987, Lovaas published an article which introduced a new treatment approach describing a significant improvement of IQ scores and educational functioning in almost $50 \%$ of children with ASD [9]. Also known as The Lovaas Method of Applied Behavior Analysis, and subsequently as discrete trial training (DTT), it is an intensive, highly structured, long-term, one-on-one behavior intervention designed for young children, which has a strong empirical support and has become the foundation for many of the evidencebased behavioral interventions in use today [10]. Subsequently, through decades of extensive research, a number of modifications and adaptations of the Lovaas method have since been developed. These can be used in different settings, environments, and procedures, and have been shown to be effective in addressing the core impairments of ASD in social communication, speech, behaviors, play, and learning [11-14].
Odom et al. [13] and Wong et al. [15] have classified behavioral evidence-based interventions into two groups: comprehensive treatment models (CTMs) and focused interventions.

Comprehensive treatment models focused on core ASD symptoms have been found to improve language, cognitive, and functional language skills in young children, using intensive and long-term multi-disciplinary strategies in naturalistic environments. Instructions can be provided at home or in a classroom setting, individually or in a group, provided by instructors or by parents. Examples of well-established CTMs include Early Behavior Intervention (EIBI) [16], Early Start Denver model (ESDM) [17], Developmental, Individual difference, relationship-based model (DIR/Floortime, or Greenspan model) [18], Pivotal Response Training (PRT) [19], and Treatment and education of autistic and related communication handicapped children (TEACCH) [20].

Focused interventions address a single skill or a specific area of developmental domain and are provided for a short time, until the skill is mastered. They can also be effective to address life-threatening or socially inappropriate behaviors that require rapid addressing. Examples include social skill training, toilet training, modeling, cognitive behavioral intervention, and behavioral strategies like prompting, ignoring, time delay, reinforcement, discrete trial teaching, and extinction. These can be implemented as a structured session or in a naturalistic setting at home, school, clinic, or community settings, with peers or parents, and have behavioral, developmental, or educational purposes. Peer-mediated Instruction and Intervention (PMII), also known as "Peer Modeling," "Peer Initiation Training," "Peer support" [21, 22], and Picture Exchange Communication System (PECS) [23], are also other examples of focused interventions.

Behavioral interventions work most effectively when started at an early age and the majority cater to young children to optimize their development and learning skills. The sociocultural beliefs and economic capability of the family also moderate treatment impact and outcome [24]. However, behavioral interventions do have a role in older children, adolescents, and adults as well; the targets of these interventions change in older individuals to include social, vocational, leisure skills, and independent living. Research in behavioral interventions for adults with ASD is still limited and will need to be expanded in future.

\section{Established Psychopharmacological Treatments}

The use of psychotropic medications has markedly increased over the last decades; approximately two-thirds of autistic adolescents have been treated with psychotropic 
medications, especially those with challenging behaviors and co-occurring conditions like intellectual disability (ID), medical, and mental health diagnoses. Co-occurring mental health conditions have been reported in approximately $70 \%$ of autistic individuals ranging from attention deficit and hyperactivity disorder (ADHD), irritability, aggression, mood, and anxiety issues $[8,25,26]$. Mandell et al. reported that $56 \%$ were prescribed at least one psychotropic medication and $20 \%$ were prescribed three or more [27]. Individuals with ASD frequently are treated with multiple medications, including off-label use (e.g., use of antipsychotic medications in younger children). Studies have reported high rates of polypharmacy ranging from 12 to $35 \%$ based on the type of studies $[28,29]$. The increasing prescription rates for individuals with ASD is not completely understood. For instance, some authors have postulated that this may be influenced by improvements in diagnostic and clinician awareness of co-occurring mental health issues [25]. However, other researchers have reported demographic factors influencing pharmacological treatment. For instance, in a large study, those who were uninsured or exclusively privately insured were less likely to use more than 3 medications than were those insured by Medicaid [30]. Prescription medications may also be affected by demographic factors including race, ethnicity, and geography. Studies have reported that challenging behaviors and mental health diagnoses are influencing factors [29]. For example, polypharmacy is often necessary since one treatment for anxiety may not be helpful for another comorbid condition such as ADHD. Such polypharmacy will be more common as specific treatments for dysfunctional pathways are utilized which go hand in hand with other treatments for common comorbidities of ASD. An example is metformin which can downregulate the mTOR pathway, and this treatment works well with stimulants for ADHD and also Selective Serotonin Reuptake Inhibitors (SSRIs) for anxiety.

Prescribers must consider medications not only for symptoms of associated psychopathology but also as targeted treatments that have the potential to reverse the neurobiological abnormalities and should be considered as a part of an individualized therapeutic program with behavioral and educational interventions.

\section{General Principles in Using Pharmacological Treatment in ASD}

Frequently, identification and management of psychiatric issues can be complex, especially for those with limited language repertoire, low cognitive function, and those experiencing uncertain symptoms. Diagnostic overshadowing is common (failure to identify other conditions in the presence of a certain diagnosis). A high level of clinical suspicion for co-occurring mental health conditions is required for children and adolescents with communication challenges. Managing clinicians should obtain information from the child, when possible, family and other providers including teachers and therapists. Environmental changes and lack of skills can be the source of undesired behaviors and should be considered in the plan of care.

Pharmacological interventions are sometimes indicated and may facilitate their participation in therapy and enhance their daily functioning. The principles used for psychopharmacological management are the same for children with ASD as for those with typical development. However, prescribers should keep in mind that children with ASD tend to be more sensitive to medication effects and more likely to have adverse effects than children without ASD. Therefore, pharmacological treatment should be started at lower doses, and adjusted more slowly than in neurotypical children. Obtaining objective symptom measures from different sources before and after the intervention is key to objectively evaluate the response of treatment in different settings.

\section{Serotoninergic Medications}

Serotoninergic medications regulate the levels of serotonin which is a key messenger specially involved in the gastrointestinal, cardiovascular, and the central nervous system (CNS). The serotonin level has been reported to be elevated in the autistic population, and it has been theorized that serotonin dysregulation is associated with symptoms frequently seen in autistic individuals ranging from repetitive behaviors to anxiety. PET studies have demonstrated that young children (under 5 years old) with ASD have lower levels of serotonin in the CSF [31]. Studies of lymphoblastoid cell lines in patients with ASD compared to controls have demonstrated a deficit of enzymes that convert tryptophan to serotonin [32]. These studies suggested that those with ASD would benefit from treatment with an SSRI to stimulate neurogenesis and neuroprotection [33]. There are three different groups of medications that influence the serotonin levels: the SSRIs, SNRIs (serotonin-norepinephrine reuptake inhibitors), and tricyclic antidepressants. The SSRIs are one of the most commonly prescribed medications for autistic individuals to treat anxiety, mood issues, and irritability. However, results of available clinical trials have been inconsistent in the benefits of SSRI's for improving aggression and the core symptoms of ASD [34].

A retrospective study of children with FXS (ages 12 to 50 months) demonstrated improvement in the trajectory of both receptive and expressive language measures on the Mullen Scales of Early Learning (MSEL) in those treated with low-dose sertraline vs those who did not receive sertraline [35]. These results led to a controlled trial for 6 months of sertraline in children ages 2 to 6 with FXS (60\% also had ASD) treated clinically with low dose 
sertraline ( 2.5 to $5.0 \mathrm{mg} /$ day) [36]. Those treated with sertraline demonstrated greater improvement in motor and visual subtests and the Cognitive T score on the MSEL compared to those on placebo. In the children with both FXS and ASD, there was also significant improvement on the Expressive Language subscale compared to placebo [36]. In the same controlled trial, a passive visual eye tracking measure of receptive vocabulary was also significantly improved in those treated with sertraline compared to placebo [37]. These studies suggest that young children with FXS both with and without ASD benefit from low-dose sertraline treatment. However, a similar study in young children ages 2 to 6 with idiopathic ASD (without FXS) treated with low-dose sertraline did not demonstrate a benefit of sertraline compared to placebo [38]. Therefore, the genetic subtype of ASD makes a difference in response to treatment and all children diagnosed with ASD must have genetic testing including Fragile X DNA testing and a CGH array for starters and subsequent whole exome sequencing (WES) or whole genome sequencing (WGS) if the initial studies are negative [39].

\section{Atypical Antipsychotics}

There are two medications approved by the FDA for the treatment of irritability associated with ASD: risperidone, approved for children older than 5 years of age [40], and aripiprazole, approved for children 6 to 17 years of age [41]; clinical trials found them to be effective in reducing irritability and, to a lesser degree, repetitive behaviors. These two atypical antipsychotic medications have affinity for dopamine, 5-HT, alpha-adrenergic, and histaminergic receptors in the brain. They also share similar safety profiles; the most common side effects include fatigue, increased appetite, GI symptoms, hyperprolactinemia, weight gain, and sedation, and less commonly activation including restlessness and akathisia. They are also linked to more serious side effects including dyslipidemia, hyperglycemia, metabolic syndrome, and extrapyramidal symptoms or drug-induced movement disorders. Therefore, close clinical and laboratory monitoring is recommended. Given that the efficacy and safety of these medications have not been established for the long-term treatment of irritability in autistic individuals, it is important to periodically re-evaluate the need for continuation of treatment. Since the development of atypical antipsychotics, the use of the conventional antipsychotics has been reserved for more severe cases refractory to the newer generation medications, due to the narrower safety profile and greater incidence of adverse reactions including extrapyramidal symptoms such as tardive dyskinesia with conventional antipsychotics.

\section{Stimulant Medications}

Stimulants are usually the first line of treatment to treat co-occurring attention deficit and hyperactivity disorder (ADHD) as they present with a rapid clinical effect and there is enough data supporting their use and safety. Approximately half of autistic children also meet criteria for ADHD [42], but prevalence widely varies based on samples [8, 43-47]. Treating co-occurring ADHD symptoms in autistic individuals should focus on improvement in enhancing their daily function in multiple settings, including learning, and hopefully long-term functional outcomes improving associated symptoms causing impairment in the academic setting, peer relationships, and emotional regulation, which are also key predictors and mediators of functional difficulties in adulthood. Before starting a patient on a regimen, the prescribing clinician should assess the potential risks for pharmacotherapy by obtaining a complete past medical history, family history, and a physical examination with a specific focus on the cardiovascular system. It is important to obtain pretreatment baseline information and a close follow up to objectively evaluate the impact of common side effects associated with pharmacotherapy for ADHD (i.e., appetite changes, hypertension, weight loss, sleep disturbances, headaches, abdominal pain). Baseline sleep problems do not appear to predict stimulant-related sleep problems and may improve with stimulant therapy [48]. Adolescent patients should be assessed for substance use or abuse prior to starting treatment.

There are two main stimulant families: the amphetamines are usually slightly more efficacious than the methylphenidate derivates which are usually better tolerated [49]. In a systematic review and network meta-analysis that included 81 published and unpublished randomized trials in $>10,000$ neurotypical children, amphetamines were slightly more efficacious than methylphenidate in reducing clinician-rated core symptoms of ADHD at approximately 12 weeks; however, amphetamines were less tolerable than placebo and methylphenidate was better tolerated than amphetamines [49]. Specific systematic review of four-crossover trials in autistic children (113 participants) age 5 to 13 years found low-quality evidence that short-term treatment with methylphenidate may improve hyperactivity and inattention in children with ASD, and the only significant adverse side effect was reduced appetite as rated by parents; however, there was no evidence of impact on core ASD symptoms or improvement in social interaction [50]. In the largest crossover trial, approximately $50 \%$ of children with ASD responded to methylphenidate based on the hyperactivity subscale of the Aberrant Behavior Checklist (ABC); the effect size ranged from 0.20 to 0.54 , depending upon dose and rater, with greater improvement at higher doses; then, this modest effect supports that Methylphenidate exerts a 
lower effect on primary ADHD symptoms in individuals with ASD compared to those in the neurotypical population. Six of 66 children in the double-blind phase $(9.1 \%$;) discontinued treatment due to adverse effects, including irritability, repetitive behaviors, tics, insomnia, and reduced appetite [51].

Treatment failure is defined by lack of satisfactory improvement in core symptoms of ADHD at the maximum dose or the occurrence of intolerable adverse effects. At least half of the children who presented with an inadequate response or side effects to a certain medication may respond well to another one. For those children failing to respond to two different medications, the prescriber should evaluate other causes for the limited therapeutic response including (1) the presence of comorbid psychiatric diagnosis, (2) unrealistic expectations about the expected clinical response, (3) misuse or medication diversion, and (4) lack of adherence to the regimen. Children on stable maintenance dose should be followed every 6 months to monitor side effects and evaluate clinical response.

\section{Alpha-2-adrenergic Agonists}

There is also evidence about the use of alpha 2 agonists to improve core ADHD symptoms, but alpha-2-adrenergic agonists (i.e., guanfacine and clonidine) are frequently used in children under 5 year old with ADHD or hyperarousal, cases with poor response to a trial of stimulants, or selective norepinephrine reuptake inhibitors, have unacceptable side effects, or have significant co-occurring conditions (i.e., sleep issues). However, studies of alpha-2-agonists in ASD are limited and have small sample sizes. Guanfacine has been reported to be safe and effective in the treatment of hyperactivity and impulsiveness in children with ASD [52, 53]. The most common side effects of guanfacine include sedation, constipation, irritability, and aggression. A small crossover study has also suggested positive effects of clonidine in ASD including decreased irritability, stereotypy, hyperactivity, inappropriate speech, and hyperarousal behaviors [54].

Data from randomized trials, systematic reviews, and meta-analyses show that atomoxetine and alpha-2-adrenergic agonists are more effective than placebo in reducing the core symptoms of ADHD, but as a class, they are less effective than stimulants $[49,55,56]$. Similarly, it is key to obtain objective targeted symptom measures at baseline and during treatment to objectively evaluate the response to treatment in different settings.

In a recent review of nine controlled trials of 430 children with ASD comparing the response between methylphenidate, atomoxetine, and guanfacine, methylphenidate and atomoxetine had superior effects than placebo in addressing ADHD symptoms; however, the response for hyperactivity symptoms was less than observed in neurotypical populations with both medications [57]. Worse treatment outcomes were associated with individuals with lower cognitive functioning.

\section{Melatonin}

Sleep issues are frequently reported in children with ASD potentially affecting their behavior, daily functioning, and family life. There is some evidence suggesting that low melatonin levels affect the circadian rhythm in autistic children [58]. In cases where behavioral and environmental sleep interventions have been implemented with limited response, clinicians may recommend the use of melatonin which is usually well tolerated and has a low incidence of side effects [59]. There is increasing evidence for the use of prolonged-release melatonin in autistic individuals with limited response to regular release formulations [60]. Melatonin is an over-the-counter product that is not regulated by the FDA. When parents/caregivers purchase melatonin, they should seek a formulation that contains melatonin as the only active ingredient.

\section{$\mathrm{N}$-acetylcysteine}

$\mathrm{N}$-acetylcysteine (NAC) is another antioxidant that can be purchased over the counter (OTC), and it can improve the imbalance of excitation: inhibition (E:I) that is seen in some forms of ASD [61]. NAC works by two mechanisms to lower the E:I imbalance; it lowers glutamatergic neurotransmission, and the cysteine leads to an increase in glutathione synthesis which is an important antioxidant. Cysteine is also oxidized to cystine, which further helps to reduce glutamatergic neurotransmission [62]. Hardan and colleagues carried out a controlled trial of escalating doses of NAC from $900 \mathrm{mg}$ once a day for 4 weeks, increasing to bi-daily dosing for 4 weeks and then tri-daily dosing for the last 4 weeks compared to placebo. They randomized 33 subjects with ASD ages 3.2 to 10.7 years and after 12 weeks of treatment they found significant improvement on their primary outcome measure, irritability subscale on the ABC $(p<0.001)$ for patients treated with NAC compared to placebo. Additional improvements were seen in stereotypic behaviors with significance reached on the RBS-S Stereotypies subscale $(p<0.014)$ and the SRS Autism Mannerisms subscale $(p<0.045)$ for those treated with NAC vs placebo [62]. NAC was well tolerated although an occasional patient did not like the taste or had minimal gastrointestinal side-effects.

\section{Dietary Supplements}

Sulforaphane is a naturally occurring isothiocyanate (found in broccoli and other cruciferous vegetables) [63-65]. Sulforaphane is an antioxidant, anti-inflammatory, and 
mitochondrial protective agent that has been studied in several animal models and humans with neurodegenerative and neurodevelopmental disorders [66]. Sulforaphane is a sulfur-rich dietary phytochemical which can penetrate the blood brain barrier, and it subsequently induces the nuclear factor erythroid 2 related factor 2 ( Nrf2) signaling cascade that stimulates the expression of more than 200 genes that are antioxidants and involved in detoxification and neuroprotection in the CNS [67]. The effect leads to reduction of superoxide and other reactive oxygen species (ROS), upregulation of the proteozome system to digest unfolded or misfolded proteins, enhancement of autophagy, inhibition of pro-inflammatory cytokines, protection from heme toxicity, and defense of neuronal cells from $\mathrm{A} \beta_{42}$-mediated cytotoxicity.

There have been a few studies in patients with ASD [68, 69] including a controlled trial of young men ages 13 to 27 with moderate to severe ASD treated with sulforaphane $(n=29)$ compared to placebo $(n=15)$ for 18 weeks. Significant improvements were seen on the Aberrant Behavior Checklist (ABC), the Clinical Global Improvement Scale (CGI-I), and the Social Responsiveness Scale 2 (SRS) [69]. This positive trial lead to a more detailed study in children with ASD, a randomized controlled trial of sulforaphane lasting 15 weeks followed by an open label trial for another 15 weeks in 57 children ages 3 to 12 years [70]. Although the primary outcome measure, the Ohio Autism Clinical Impressions Scale, did not improve significantly in those on sulforaphane, a secondary measure, the $\mathrm{ABC}$, did significantly improve on sulforaphane vs placebo but the SRS did not. In addition, there were significant improvements in the biomarkers including the glutathione redox status, mitochondrial respiration, inflammatory markers, and heat shock proteins on sulforaphane vs placebo, and these improvements correlated with improvements on the ABC. They utilized a commercial product of sulforaphane called Avmacol made by Nutrimax with a tablet dose of 2 to 8 tablets per day depending on the weight of the child (equivalent to $2.2 \mu \mathrm{mol} / \mathrm{kg} /$ day). There were no significant adverse events and the supplement was well tolerated.

Other antioxidants have been studied in ASD including omega-3 fatty acids [71, 72] with mixed results, and these antioxidants promote glutathione recycling by facilitating the conversion of oxidized glutathione into reduced glutathione. A more recent study was carried out by Mazahery et al. [73] in 111 children with ASD ages 2.5 to 8 years, and they were randomized to placebo, Vitamin D 2000 IU/day, or omega- $3722 \mathrm{mg} /$ day or both interventions for 1 year of treatment. Seventy-three patients completed a year of therapy, and those on both treatments had a significant reduction in their primary outcome measure, irritability on the $\mathrm{ABC}$ subscale $(p<0.001)$ compared to placebo, and those treated with vitamin $\mathrm{D}$ alone also had a reduction in irritability also compared to placebo $(p<0.45)$ [73]. These studies suggest that antioxidants may be a helpful ancillary treatment in some patients with ASD, although biomarkers of oxidative stress would be helpful to assess in further studies to better identify those who would benefit from this treatment.

\section{Emerging Targeted Treatments with a Possible Role in ASD}

\section{Oxytocin}

Oxytocin (OXT) is a neuropeptide synthesized in the hypothalamus that plays a critical role in social functioning. Extant literature has shown that OXT enhances social processing in typically developing adults (enhanced eye contact, better emotion recognition in faces) immediately after its administration [74]. There have been generally positive results of OXT in adults with ASD, with trials showing improvements in repetitive behaviors, social reciprocity, and emotion recognition [75-77]. However, all these trials studied only short-term benefits (within a few weeks) of OXT administration. A recent randomised, placebo-controlled, double-blind study in adults with ASD showed improvements in self-reported repetitive behaviors and positive mood at 1 year post treatment after an initial 4 weeks of oxytocin treatment [78]. However, in this same study, there were no significant treatment benefits for social responsiveness with OXT [78]. Another recent study in young adults with ASD also did not demonstrate any immediate benefits of OXT on empathy and social perception [79].

Results of OXT studies in children have overall been more equivocal with mixed results. Although 4 studies showed positive short-term results of OXT administration on social responsiveness (following 4 or 5 weeks of OXT administration) [80-83], another 2 studies did not demonstrate any OXT specific improvements in social responsiveness or repetitive behavior in children with ASD [84, 85]. A recent randomized controlled trial (RCT) however did not show any significant effects between the OXT and placebo group in aberrant behavior, social communication, or cognition [86]. At the neural networks level, it has been shown that intranasal OXT leads to increased activation in the brain regions known to be involved in perceiving and thinking about social-emotional information and enhances effective connectivity between nodes of the brain's reward and socioemotional processing systems [87, 88]. There were no noted side effects in these studies on children with ASD, thus far, although animal studies have raised the possibility of increased basal OXT levels with long-term OXT administration; the clinical effects of this being unclear. Of pertinence, there remains a lack of conclusive evidence for the long-term beneficial effects of OXT in addressing the 
core symptoms of autism [89]. Given that the vast majority of studies in children utilize parent-reported outcome measures of social and behavioral symptoms, inherent limitations of bias in reporting even in placebo-controlled trials are likely to come into play. Another important consideration is whether the gains that are seen with OXT administration in the experimental setting translate to real life and this is also unclear. The role of OXT thus far has been limited to its immediate effect after administration and hence is not a single treatment option for ASD. Nonetheless, as illustrated by a recent meta-analysis, there does seem to be overall beneficial effects of OXT on social symptoms of ASD, although this review included both children and adults [90]. There is also some promising research looking at the role of OXT in combination with other treatment modalities including behavior therapy and probiotics, with clinical trials in this area ongoing [91, 92]. It is also likely that the effects of OXT in ASD are modulated by age, gender, and possibly genetic factors $[77,79,90]$. As such, although it holds much promise, the use of OXT in individuals with ASD is currently not a mainstream treatment.

\section{Bumetanide}

Bumetanide is a well-established loop diuretic that works by inhibiting sodium-potassium-chloride co-transporters, namely, NKCC1 and NKCC2. Bumetanide has been purported as a potential treatment in autism due to its inherent chloride-related antagonist effects which is linked to GABAergic inhibition [93]. Bumetanide has been shown to reduce broad ASD symptomatology in children following a 3-month treatment course in 2 placebo-controlled randomized controlled trials $[94,95]$. Both of these trials used outcomes that are screening tools for ASD, namely, the SRS and the Childhood Autism Rating Scale (CARS). Another open-label trial of 6 children with severe ASD and intellectual disability showed parent-reported improvement in communicative abilities of all children after 3 months of bumetanide [96]. However, a recent double-blind, placebo-controlled, phase 2 superiority trial in children with ASD without severe intellectual disability did not show any treatment benefits on the core symptoms of ASD as measured on the SRS-2 [97]. It did show treatment benefits on the repetitive behavior scale, with no major adverse effects. Another study has suggested possible combined effects of bumetanide with ABA therapy in improving ASD symptoms on the CARS, although this was not a randomized controlled trial [98]. There are 2 phase 3 clinical studies ongoing now, which may shed further information on the potential benefits of bumetanide in ASD [99]. There is some functional-MRI-based evidence suggesting that bumetanide reduces the exaggerated amygdala activation to eye contact in individuals with ASD and contributes to increased eye-gaze time with biological stimuli and better emotional face perception [100, 101]. Regardless, based on current literature, there is inconclusive evidence for the role of bumetanide in addressing the core symptoms of ASD [102, 103].

\section{Metformin}

Targeted treatments that reverse known neurobiological abnormalities in subgroups of ASD where there is also animal data to demonstrate benefit have emerged in the last decade for subgroups of ASD. The subgroup of ASD that is leading the way in targeted treatments is FXS, the most common single gene cause of ASD. In addition, post mortem studies have shown that FMRP, the protein that is missing or deficient in FXS, is also deficient in the brain in patients with idiopathic ASD without a fragile X mutation [104, 105]. Therefore, FXS is a model for targeted treatments in other subtypes of ASD and treatments that work well in FXS may also be beneficial for other forms of ASD. So we will describe some of the targeted treatment studies with compounds that are available currently, although not FDA approved for FXS nor ASD.

Animal studies in FXS have demonstrated a hyperactive insulin receptor and up-regulation of the mammalian target of rapamycin complex 1 (mTORC1) and mitogen-activated protein kinase/extracellular signal-related kinases (MAPK/ ERK) signaling pathways, as well as elevation of MMP-9 levels in the absence of FMRP, the protein produced by the FMRI gene [106-108]. Metformin is a bi-guanide that is a primary treatment for type 2 diabetes, but it can also reduce the appetite in individuals with obesity. Therefore, studies of metformin were first carried out in patients with FXS who demonstrated obesity, often with the Prader-Willi-phenotype of FXS [109]. In a handful of patients with FXS treated clinically with metformin between the ages of 4 and 60 years old, there was improvement in overeating but also on the $\mathrm{ABC}$ subscales of irritability, aggression, and social avoidance [109]. Parents also stated that they saw improvement in the expressive language abilities in conversation. The potential language improvements are currently being studied in a controlled trial of metformin occurring over 3 sites, 2 in Canada (Edmonton and Montreal), and one site in the USA at the MIND Institute funded by the Azrieli Foundation (NCT03479476, NCT03862950). Patients ages 6 to 45 are recruited into a randomized controlled trial lasting 4 months with outcome measures including the Expressive Language Sampling as the primary outcome but also event related potentials, eye tracking, NIH toolbox, and other behavioral measures are assessed. The results will be available in 2022. Additional open label studies have been carried out with metformin including one in children ages 2 to 7 years old with FXS, and improvements were seen in behavior and development on the MSEL [110]. Individual case studies 
have shown that macroorchidism did not develop in boy who started metformin clinically before puberty [111] and two adults with FXS improved their IQ when using metformin for over one year [112].

\section{Lovastatin}

Lovastatin is a commonly used statin that lowers cholesterol levels, but it does this by inhibiting 3-hydroxy-3methylglutaryl coenzyme A (3HMG-CoA) reductase, and it is FDA approved for lowering hypercholesterolemia or hyperlipidemia in children and adults. This action lowers the excessive protein production of the MEK-ERK pathway which are elevated in FXS. Studies of lovastatin treatment in the FXS knock out (KO) mouse rescued excess protein synthesis and also epilepsy [113]. These animal studies stimulated FXS patient trials. The one controlled trial included 32 children with FXS between 10 to 17 years treated in a RCT for 20 weeks with a dose of 10 to $40 \mathrm{mg}$ a day as tolerated [114]. In addition, the patients all received Parent Implemented Language Intervention (PILI) [115] delivered by distance video teleconferencing over 12 weeks by a speech and language therapist with 4 sessions per week. Parents were taught a set of language facilitation techniques that were utilized with shared story telling sessions with their child. The main outcome measures were the number of utterances and new words utilized in addition to additional language scales, behavioral measures (ABC), and the CGI-I. So this study compared the combined effects of lovastatin plus PILI to PILI alone with placebo. Remarkably, there was significant improvements from baseline in both groups, but the outcomes were the same in both groups; that is, PILI alone had as much improvement as lovastatin plus PILI demonstrating the power of intensive language intervention [114].

\section{Cannabidiol}

Cannabidiol (CBD) is a phytocannabinoid found in Cannabis sativa, marijuana. Although there are hundreds of phytocannabinoids in marijuana, CBD is the second most common one after delta-9-tetrahydrocannabinol (THC) which has psychotropic properties. Marijuana has been used for 8000 years in India, China, and Middle East for fiber and medicinal properties; then introduced to Europe in early nineteenth century by Napoleon's army returning from Egypt and then to Britain for medical use by a surgeon who served in India. CBD is the non-psychotropic component of marijuana, and there are numerous therapeutic effects of this drug including treatment of anxiety, pain, nausea, and motor deficits including the tremor in Parkinson's disease [116]. CBD has both neuromodulatory and neuroprotective effects through a number of mechanisms including blocking neuroinflammation and potentiating anti-inflammatory pathways, improving mitochondrial function, $\mathrm{GABA}_{\mathrm{A}}$ agonist potentiation, stimulation of $5 \mathrm{HT}_{1 \mathrm{~A}}$ receptors, and enhancing levels of anandamide (AEA) [116-119].

The endocannabinoid system has two receptors $\mathrm{CB}_{1}$ found primarily in the $\mathrm{CNS}$ and $\mathrm{CB}_{2}$ found throughout the body and the immune system. The primary endogenous ligands for $\mathrm{CB}_{1}$ and $\mathrm{CB}_{2}$ receptors are called endocannabinoids (ECs) and include anandamide AEA and 2arachidonoylglycerol (2-AG). The ECs modulate synaptic transmission throughout the CNS, yielding widespread influence on cognition and behavior. The ECs are synthesized and released from post-synaptic membrane-bound phospholipids in response to neuronal signaling and act as retrograde signaling molecules across the synaptic cleft to stimulate $\mathrm{CB}_{1}$ receptors on the presynaptic terminal, and they can inhibit neurotransmitter release from the presynaptic terminal. Enzymes that function in synthesizing 2-AG include phospholipase $\mathrm{C}$ and diacylglycerol lipase (DAGL).

CBD has also been shown to act as a positive allosteric modulator at $\mathrm{GABA}_{\mathrm{A}}$ receptors, and controlled trials have shown that $\mathrm{CBD}$ in the form of Epidiolex is an effective anticonvulsant in Dravet syndrome and Lennox-Gastaut syndrome [120]. CBD's ability to enhance endocannabinoid levels and facilitate GABAergic transmission may serve to improve the balance in inhibitory and excitatory transmission and help restore neuronal function and synaptic plasticity in patients with ASD and FXS even when there is no epilepsy. Animal models of both FXS and ASD have shown benefits when treated with CBD [121, 122]. Studies of individuals with ASD treated with CBD and open label trials of CBD are reviewed by Nezgovorva et al. [123]; however, the preparations studied have both CBD and variable levels of THC, although in general, benefits were seen in irritability, sleep disorders, tantrums, and anxiety. Currently, studies of cannabidavarin (CBDV) are taking place in ASD and CBDV has also been helpful in animal models of ASD [123].

Recently, the development of a topical CBD that is manufactured so that there is no THC has facilitated studies in both ASD and in FXS. The BRIGHT study was an open label study of children ages 3 to 17 with ASD lasting 14 weeks, and benefits were seen in most outcome measures including the $\mathrm{ABC}$ and measures of anxiety [124]. Currently, a controlled trial of this topical CBD called Zyn002 is taking place in children with ASD. Another recent randomized controlled trial (RCT) looking at an oral preparation of CBD in children and young adults with ASD demonstrated positive improvements in behavior and social communication with CBD [125].

Huessler et al. [126] carried out an open label trial of Zyn002 in Australia for children with FXS of ages 3-17 years old with doses of the transdermal CBD at doses $250 \mathrm{mg}$ bi-daily for 12 weeks (ACTRN12617000150347). Both the primary outcome, the Anxiety Mood and Depression (ADAMS) scale and the secondary measures including 
the $\mathrm{ABC}$, demonstrated efficacy. Subsequently, a multicenter controlled trial of over 200 children with FXS was carried out and efficacy was seen in only those children with $>90 \%$ methylation with FXS on the primary outcome measure of the Social Avoidance subscale of the $\mathrm{ABC}_{\mathrm{FX}}$, a scale that has been developed for FXS modified from the ABC (BerryKravis et al. 2022 under review Sci Trans Medicine). Currently, the FDA has not approved Zyn002 for general use, but an additional multicenter controlled trial is now taking place to win this approval. It is very likely that the current controlled trials taking place for ASD and FXS will show efficacy for subgroups for both disorders, and subsequently, CBD will be more broadly utilized.

\section{Arbaclofen}

Arbaclofen, also called STX209, is a selective $\mathrm{\gamma}$-aminobutyric acid type $\mathrm{B}$ receptor agonist that is the R-enantiomer of racemic baclofen. For many subtypes of $\mathrm{ASD}$, there is a $\mathrm{GABA}_{\mathrm{B}}$ deficit and arbaclofen has rescued the behavioral deficits including social deficits in the mouse models of idiopathic ASD [127], deletion of 16p11.2 [128], and FXS [129]. There are 3 pathways that are improved with arbaclofen: Stimulation of presynaptic $\mathrm{GABA}_{\mathrm{B}}$ receptors inhibits glutamate release thereby lowering the mGluR5 pathway. Stimulation of GABA receptors also improves inhibition that is down-regulated in many forms of ASD and arbaclofen also enhances $\mathrm{K}$ channel activation which can also be down-regulated in many forms of ASD [130]. The promising mouse studies led to human trials in FXS [131] that initially showed improvements in those with ASD plus FXS leading to phase 3 trials in FXS [132]. However, the adult studies of FXS did not demonstrate efficacy and the pediatric trials did not reach significance for the primary outcome measure, but did show limited improvements in secondary measures including the Parenting Stress Index because of lowered irritability in the children [132].

Both open label studies in idiopathic ASD and in those with a 16p11.2 deletion have been carried out with positive behavioral benefits. A controlled trial with idiopathic ASD has also been started but not yet reported. Arbaclofen has been well tolerated even at higher doses up to $15 \mathrm{mg}$ tri-daily so it is likely that further studies will be carried out both in ASD and in subtypes of ASD including FXS.

\section{Trofinetide}

Insulin like growth factor 1 (IGF1) is considered an emerging treatment for ASD in animal and cellular models in ASD [133-136]. Trofinetide is an analogue of the amino-terminal tripeptide of IGF1, and it has been studied in patient groups of ASD subtypes. Trofinetide is glycyl-L-2-methylprolylL-glutamic acid, and it was studied in a controlled phase 2 trial in 82 children with Rett syndrome ages 5 to 15 years, and significant benefit was found in the high-dose group (200 mg/kg/day) compared to placebo [137]. Significant benefits were seen in several measures including the Rett Syndrome Behavior Scale, the Rett Syndrome Clinician Rating Scale, and a visual analogue scale. This report led to a multicenter phase 3 controlled trial in Rett syndrome which is ongoing currently.

Trofinetide has also been studied in a 28-day controlled trial in adolescent and adult patients with FXS [138]. Patients were randomized to trofinetide $35 \mathrm{mg} / \mathrm{kg} /$ day, $70 \mathrm{mg} / \mathrm{kg} /$ day, or placebo. Results demonstrated that the $70 \mathrm{mg} / \mathrm{kg} /$ day was significantly beneficial compared to placebo with a permutation test utilizing the primary components of the Fragile X Syndrome Rating Scale, a Fragile $X$ Specific Domain Scale on a visual analogue format, and the $\mathrm{ABC}_{\mathrm{FX}}$.

In the fragile $\mathrm{X}$ knockout $(\mathrm{KO})$, mouse studies trofinetide had several positive effects at a dose of $100 \mathrm{mg} / \mathrm{kg} / \mathrm{day}$ yielding insight as to why it is beneficial in FXS [139]. The KO mouse was deficient in IGF1 in the brain, and this was normalized with trofinetide treatment for 28 days. Improvements in dendritic spine abnormalities, astrogliosis, neuroinflammation, glial activation, and downregulation of the MEK-ERK and PI3K-mTOR pathways were seen with trofinetide treatment leading to improvements in behavior and morphology of FXS [139]. Clearly, trofinetide is a treatment that improves multiple pathways that are dysregulated in more than one subtype of ASD and further studies at optimal doses will be carried out and some are currently taking place.

\section{Phosphordiasterase 4D Inhibitors}

It has been known for many years that cAMP, an important energy compound for improving synaptic connections, is down regulated in FXS [140]. Recent animal studies have shown that an inhibitor of cAMP breakdown called a phosphordiasterase 4DE inhibitor can rescue features of FXS in the KO mouse model and Drosophila model and can raise the cAMP levels to normal [141, 142]. These studies led to patient trials of a PDE4D inhibitor called BPN14770, and an exciting study was recently published, a randomized controlled trial in 30 adult males with FXS that demonstrated improvements not only in behavior but also in the primary outcome measure, the NIH toolbox, and secondary measures after only 12 weeks of treatment [143]. This is the first treatment of FXS that demonstrated improvements in cognition, specifically in Oral Reading Recognition, Picture Vocabulary and Cognition Crystallized Composite Score in the NIH toolbox that has been modified for use in those with ID. The caregivers also used the Visual Analog Caregiver Rating Scales and demonstrated improvement in language and daily 
functioning. Families are excited that this is the first of hopefully many new medications that can reverse cognitive deficits and further controlled trials are in the planning stages.

\section{Anavex 2-73}

Anavex 2-73 (AV 2-73; Blarcamesine) is a sigma 1 receptor agonist that works between the endoplasmic reticulum and the mitochondrial membrane to normalize calcium dysregulation, oxidative stress, and mitochondrial dysfunction which is seen in many forms of ASD. It has demonstrated significant benefits in the KO mouse model of FXS where multiple behaviors were improved and deficient brain derived neurotropic factor (BDNF) levels were normalized [144]. In addition, Kaufman et al. [145] also reported significant benefits in the Rett syndrome mouse model with a rescue of behavior and BDNF levels and this work lead to patient studies in Rett syndrome that have demonstrated efficacy in a controlled trial (Anavex Life Sciences press release 2021). AV2-73 also has beneficial effects in neurodegenerative disorders because of improvement in proteostasis, autophagy, oxidative stress, prevention of protein aggregates, and improvement in mitochondrial function leading to benefits in Alzheimer' disease and Parkinson's disease dementia [146-148]. Significant potential exists for AV2-73 to improve symptoms in Fragile $\mathrm{X}$-associated Tremor Ataxia (FXTAS), a neurodegenerative disease seen in approximately $40 \%$ of older carriers of the fragile $\mathrm{X}$ premutation, because calcium dysregulation, mitochondrial dysfunction, proteostasis, and aggregations of proteins causing inclusions occur in FXTAS [149].

\section{Gene Therapy}

Although this therapy is not available for clinicians to utilize in their patients, exciting research studies particularly after the advances in CRISPR/Cas9 technology have become available. The possibility of introducing a normal gene or protein into the CNS to treat ASD or other neurodevelopmental disorders where the mutation is known is exciting. Another example of gene therapy is the introduction of antisense oligonucleotides (ASOs) to silence RNA or gene products that are deleterious. In Angelman syndrome, where the maternal copy of UBE3A is mutated or absent, ASOs have been utilized to activate the paternal copy of UBE3A in the CNS to compensate for the missing maternal copy. Recently, a controlled trial of GTX-102, an ASO, was tried in 5 individuals with Angelman syndrome ages 5 to 15 years old. The protocol involved the intrathecal injection of GTX-102 at increasing doses once monthly for 4 months. However, an adverse effect of leg weakness was seen at the higher doses leading to an inability to walk in two patients. This was found to be related to inflammation at the level where the LP was carried out so these patients were treated with anti-inflammatories with resolution of this side effect. The future is bright for further gene therapy interventions in ASD and other neurodevelopmental disorders.

\section{Conclusion}

The current evidence-based management of ASD in children relies primarily on behavioral interventions to address the core symptoms of the condition. The role of pharmacological treatments currently is primarily to address co-morbid conditions associated with ASD and increases with age. These medications including antipsychotic agents and stimulant medications are important in the clinical management of patients with ASD. However, the emergence of targeted treatments for subgroups of ASD where the genes responsible for the ASD are known and the neurobiology and potential targeted treatments have been studied to reverse the neurobiological abnormalities at least in the animal models has led to several recent achievements in patients as described here. Of note is that there are commonalities among disorders causing ASD that suggest that a targeted treatment for one disorder will be beneficial for other disorders. For instance, GABA deficits are seen in many forms of ASD and medications that are agonists for the GABA system such as CBD are likely to be helpful for many subtypes of ASD as described above. Mitochondrial dysfunction is associated with many forms of ASD, so medications that will improve mitochondrial dysfunction are likely to be helpful for many subtypes of ASD [150]. The promise of gene therapy is becoming a reality for many disorders such as Duchene Muscular Dystrophy, Spinal Muscular Atrophy, and even Angelman Syndrome because of CRISPR/Cas 9 technology so in the next few years, many additional forms of ASD will be treated with gene therapy. Until then, some of the treatments outlined here can be tried and more will become available in the near future.

Supplementary Information The online version contains supplementary material available at https://doi.org/10.1007/s13311-022-01183-1.

Required Author Forms Disclosure forms provided by the authorsare available with the online version of this article.

Funding This research was supported by grants from the Azrieli Foundation, clinical trial funding to the MIND Institute from Zynerba for the CBD study, and the MIND Institute Intellectual and Developmental Disabilities Research Center P50 HD103526.

\section{Declarations}

Conflict of Interest The authors declare no competing interests. 
Open Access This article is licensed under a Creative Commons Attribution 4.0 International License, which permits use, sharing, adaptation, distribution and reproduction in any medium or format, as long as you give appropriate credit to the original author(s) and the source, provide a link to the Creative Commons licence, and indicate if changes were made. The images or other third party material in this article are included in the article's Creative Commons licence, unless indicated otherwise in a credit line to the material. If material is not included in the article's Creative Commons licence and your intended use is not permitted by statutory regulation or exceeds the permitted use, you will need to obtain permission directly from the copyright holder. To view a copy of this licence, visit http://creativecommons.org/licenses/by/4.0/.

\section{References}

1. Maenner MJ, Shaw KA, Bakian AV, Bilder DA, Durkin MS, Esler A, et al. Prevalence and characteristics of autism spectrum disorder among children aged 8 years - autism and developmental disabilities monitoring network, 11 sites, United States, 2018. Morbidity and mortality weekly report Surveillance summaries (Washington, DC : 2002). 2021;70(11):1-16.

2. Johnson J, Spitzer R, Williams J. Diagnostic and Statistical Manual of Mental Disorders-IV TR. Washington, DC: American Psychiatric Association; 2000.

3. Hyman SL, Levy SE, Myers SM. Identification, evaluation, and management of children with autism spectrum disorder. Pediatrics. 2020;145(1).

4. Association D-AP. Diagnostic and statistical manual of mental disorders. Arlington: American Psychiatric Publishing. 2013.

5. Doshi-Velez F, Ge Y, Kohane I. Comorbidity clusters in autism spectrum disorders: an electronic health record time-series analysis. Pediatrics. 2014;133(1):e54-63.

6. Leyfer OT, Folstein SE, Bacalman S, Davis NO, Dinh E, Morgan $\mathrm{J}$, et al. Comorbid psychiatric disorders in children with autism: interview development and rates of disorders. J Autism Dev Disord. 2006;36(7):849-61.

7. Mannion A, Leader G. Comorbidity in autism spectrum disorder: a literature review. Research in Autism Spectrum Disorders. 2013;7(12):1595-616.

8. Simonoff E, Pickles A, Charman T, Chandler S, Loucas T, Baird G. Psychiatric disorders in children with autism spectrum disorders: prevalence, comorbidity, and associated factors in a population-derived sample. J Am Acad Child Adolesc Psychiatry. 2008;47(8):921-9.

9. Lovaas OI. Behavioral treatment and normal educational and intellectual functioning in young autistic children. J Consult Clin Psychol. 1987;55(1):3.

10. Slocum TA, Detrich R, Wilczynski SM, Spencer TD, Lewis $\mathrm{T}$, Wolfe K. The evidence-based practice of applied behavior analysis. The Behavior Analyst. 2014;37(1):41-56.

11. Leaf JB, Leaf R, McEachin J, Taubman M, Ala'i-Rosales S, Ross RK, et al. Applied behavior analysis is a science and, therefore, progressive. Journal of autism and developmental disorders. 2016;46(2):720-31.

12. Granpeesheh D, Tarbox J, Dixon DR. Applied behavior analytic interventions for children with autism: a description and review of treatment research. Ann Clin Psychiatry. 2009;21(3):162-73.

13. Odom SL, Boyd BA, Hall LJ, Hume K. Evaluation of comprehensive treatment models for individuals with autism spectrum disorders. J Autism Dev Disord. 2010;40(4):425-36.

14. Smith T. What is evidence-based behavior analysis? The Behavior Analyst. 2013;36(1):7-33.
15. Wong C, Odom SL, Hume KA, Cox AW, Fettig A, Kucharczyk $\mathrm{S}$, et al. Evidence-based practices for children, youth, and young adults with autism spectrum disorder: a comprehensive review. J Autism Dev Disord. 2015;45(7):1951-66.

16. Reichow B, Barton EE, Boyd BA, Hume K. Early intensive behavioral intervention (EIBI) for young children with autism spectrum disorders (ASD). The Cochrane database of systematic reviews. 2012;10:Cd009260.

17. Dawson G, Rogers S, Munson J, Smith M, Winter J, Greenson $\mathrm{J}$, et al. Randomized, controlled trial of an intervention for toddlers with autism: the Early Start Denver Model. Pediatrics. 2010;125(1):e17-23.

18. Wieder S, Greenspan SI. Climbing the symbolic ladder in the DIR model through floor time/interactive play. Autism. 2003;7(4):425-35.

19. Koegel RL, Koegel LK. Pivotal response treatments for autism: communication, social, \& academic development: Paul H Brookes Publishing; 2006.

20. Mesibov GB, Shea V. The TEACCH program in the era of evidencebased practice. J Autism Dev Disord. 2010;40(5):570-9.

21. Hume K, Steinbrenner JR, Odom SL, Morin KL, Nowell SW, Tomaszewski B, et al. Evidence-based practices for children, youth, and young adults with autism: third generation review. Journal of Autism and Developmental Disorders. 2021:1-20.

22. Hall T, Stegila A. Peer mediated instruction and intervention. Wakefield, MA: National Center on Accessing the General Curriculum Retrieved February. 2003;8:2007.

23. Bondy AS, Frost LA. The picture exchange communication system. Focus on autistic behavior. 1994;9(3):1-19.

24. Zwaigenbaum L, Bauman ML, Choueiri R, Kasari C, Carter A, Granpeesheh D, et al. Early intervention for children with autism spectrum disorder under 3 years of age: recommendations for practice and research. Pediatrics. 2015;136(Supplement 1):S60-81.

25. Feroe AG, Uppal N, Gutiérrez-Sacristán A, Mousavi S, Greenspun P, Surati R, et al. Medication use in the management of comorbidities among individuals with autism spectrum disorder from a large nationwide insurance database. JAMA Pediatr. 2021;175(9):957-65.

26. Levy SE, Giarelli E, Lee LC, Schieve LA, Kirby RS, Cunniff C, et al. Autism spectrum disorder and co-occurring developmental, psychiatric, and medical conditions among children in multiple populations of the United States. Journal of developmental and behavioral pediatrics : JDBP. 2010;31(4):267-75.

27. Mandell DS, Morales KH, Marcus SC, Stahmer AC, Doshi J, Polsky DE. Psychotropic medication use among Medicaidenrolled children with autism spectrum disorders. Pediatrics. 2008;121(3):e441-8.

28. Coury DL, Anagnostou E, Manning-Courtney P, Reynolds A, Cole L, McCoy R, et al. Use of psychotropic medication in children and adolescents with autism spectrum disorders. Pediatrics. 2012;130(Supplement 2):S69-76.

29. Spencer D, Marshall J, Post B, Kulakodlu M, Newschaffer C, Dennen T, et al. Psychotropic medication use and polypharmacy in children with autism spectrum disorders. Pediatrics. 2013;132(5):833-40.

30. Rosenberg RE, Mandell DS, Farmer JE, Law JK, Marvin AR, Law PA. Psychotropic medication use among children with autism spectrum disorders enrolled in a national registry, 20072008. J Autism Dev Disord. 2010;40(3):342-51.

31. Chandana SR, Behen ME, Juhász C, Muzik O, Rothermel RD, Mangner TJ, et al. Significance of abnormalities in developmental trajectory and asymmetry of cortical serotonin synthesis in autism. Int J Dev Neurosci. 2005;23(2-3):171-82. 
32. Boccuto L, Chen C-F, Pittman AR, Skinner CD, McCartney HJ, Jones $\mathrm{K}$, et al. Decreased tryptophan metabolism in patients with autism spectrum disorders. Molecular autism. 2013;4(1):1-10.

33. Jansson L, Louhivuori L, Wigren H-K, Nordström T, Louhivuori $\mathrm{V}$, Castrén $\mathrm{M}$, et al. Brain-derived neurotrophic factor increases the motility of a particular N-methyl-D-aspartate/ GABA-responsive subset of neural progenitor cells. Neuroscience. 2012;224:223-34.

34. Williams K, Brignell A, Randall M, Silove N, Hazell P. Selective serotonin reuptake inhibitors (SSRIs) for autism spectrum disorders (ASD). Cochrane Database of Systematic Reviews. 2013(8).

35. Indah Winarni $\mathrm{T}$, Chonchaiya W, Adams E, Au J, Mu Y, Rivera SM, et al. Sertraline may improve language developmental trajectory in young children with fragile $\mathrm{x}$ syndrome: a retrospective chart review. Autism research and treatment. 2012;2012.

36. Hess LG, Fitzpatrick SE, Nguyen DV, Chen Y, Gaul KN, Schneider A, et al. A randomized, double-blind, placebocontrolled trial of low-dose sertraline in young children with fragile X syndrome. Journal of developmental and behavioral pediatrics: JDBP. 2016;37(8):619.

37. Yoo K, Burris J, Gaul K, Hagerman R, Rivera S. Low-dose sertraline improves receptive language in children with fragile $\mathrm{X}$ syndrome when eye tracking methodology is used to measure treatment outcome. J Psychol Clin Psychiatry. 2017;7(6):00465.

38. Potter LA, Scholze DA, Biag HMB, Schneider A, Chen Y, Nguyen DV, et al. A randomized controlled trial of sertraline in young children with autism spectrum disorder. Front Psych. 2019;10:810.

39. Hagerman Ba. Pediatric and Neurological assessments In: Hollander $\mathrm{HaF}$, editor. Textbook of autism spectrum disorders 2nd edition: Am Psychiatric Assoc Publishing Washington DC; 2022. p. 87 - 100.

40. McCracken JT, McGough J, Shah B, Cronin P, Hong D, Aman $\mathrm{MG}$, et al. Risperidone in children with autism and serious behavioral problems. N Engl J Med. 2002;347(5):314-21.

41. Owen R, Sikich L, Marcus RN, Corey-Lisle P, Manos G, McQuade RD, et al. Aripiprazole in the treatment of irritability in children and adolescents with autistic disorder. Pediatrics. 2009; 124(6):1533-40.

42. Salazar F, Baird G, Chandler S, Tseng E, O'sullivan T, Howlin P, et al. Co-occurring psychiatric disorders in preschool and elementary school-aged children with autism spectrum disorder. J Autism Dev Disord. 2015;45(8):2283-94.

43. Mansour R, Ward AR, Lane DM, Loveland KA, Aman MG, Jerger $\mathrm{S}$, et al. ADHD severity as a predictor of cognitive task performance in children with autism spectrum disorder (ASD). Research in Developmental Disabilities. 2021;111:103882.

44. Sinzig J, Walter D, Doepfner M. Attention deficit/hyperactivity disorder in children and adolescents with autism spectrum disorder: symptom or syndrome? J Atten Disord. 2009;13(2):117-26.

45. Ames CS, White SJ. Brief report: Are ADHD traits dissociable from the autistic profile? Links between cognition and behaviour. J Autism Dev Disord. 2011;41(3):357-63.

46. Pondé MP, Novaes CM, Losapio MF. Frequency of symptoms of attention deficit and hyperactivity disorder in autistic children. Arq Neuropsiquiatr. 2010;68:103-6.

47. Rong Y, Yang C-J, Jin Y, Wang Y. Prevalence of attention-deficit/ hyperactivity disorder in individuals with autism spectrum disorder: a meta-analysis. Research in Autism Spectrum Disorders. 2021;83:101759.

48. Becker SP, Froehlich TE, Epstein JN. Effects of methylphenidate on sleep functioning in children with attention-deficit/hyperactivity disorder. Journal of developmental and behavioral pediatrics: JDBP. 2016;37(5):395.

49. Cortese S, Adamo N, Del Giovane C, Mohr-Jensen C, Hayes AJ, Carucci S, et al. Comparative efficacy and tolerability of medications for attention-deficit hyperactivity disorder in children, adolescents, and adults: a systematic review and network meta-analysis. The Lancet Psychiatry. 2018;5(9):727-38.

50. Sturman N, Deckx L, van Driel ML. Methylphenidate for children and adolescents with autism spectrum disorder. Cochrane Database of Systematic Reviews. 2017(11).

51. Posey DJ, Aman MG, McCracken JT, Scahill L, Tierney E, Arnold LE, et al. Positive effects of methylphenidate on inattention and hyperactivity in pervasive developmental disorders: an analysis of secondary measures. Biol Psychiat. 2007;61(4):538-44.

52. Scahill L, Aman MG, McDougle CJ, McCracken JT, Tierney E, Dziura $\mathrm{J}$, et al. A prospective open trial of guanfacine in children with pervasive developmental disorders. J Child Adolesc Psychopharmacol. 2006;16(5):589-98.

53. Posey DJ, Puntney JI, Sasher TM, Kem DL, McDougle CJ. Guanfacine treatment of hyperactivity and inattention in pervasive developmental disorders: a retrospective analysis of 80 cases. J Child Adolesc Psychopharmacol. 2004;14(2):233-41.

54. Fankhauser MP, Karumanchi VC, German ML, Yates A, Karumanchi SD. A double-blind, placebo-controlled study of the efficacy of transdermal clonidine in autism. J Clin Psychiatry. 1992;53(3):77-82.

55. Connor DF, Fletcher KE, Swanson JM. A meta-analysis of clonidine for symptoms of attention-deficit hyperactivity disorder. J Am Acad Child Adolesc Psychiatry. 1999;38(12):1551-9.

56. Hirota T, Schwartz S, Correll CU. Alpha-2 agonists for attention-deficit/hyperactivity disorder in youth: a systematic review and meta-analysis of monotherapy and add-on trials to stimulant therapy. J Am Acad Child Adolesc Psychiatry. 2014;53(2):153-73.

57. Rodrigues R, Lai MC, Beswick A, Gorman DA, Anagnostou E, Szatmari P, et al. Practitioner Review: Pharmacological treatment of attention-deficit/hyperactivity disorder symptoms in children and youth with autism spectrum disorder: a systematic review and meta-analysis. J Child Psychol Psychiatry. 2021;62(6):680-700.

58. Carmassi C, Palagini L, Caruso D, Masci I, Nobili L, Vita A, et al. Systematic review of sleep disturbances and circadian sleep desynchronization in autism spectrum disorder: toward an integrative model of a self-reinforcing loop. Front Psych. 2019;10:366.

59. Buckley AW, Hirtz D, Oskoui M, Armstrong MJ, Batra A, Bridgemohan $\mathrm{C}$, et al. Practice guideline: Treatment for insomnia and disrupted sleep behavior in children and adolescents with autism spectrum disorder: Report of the Guideline Development, Dissemination, and Implementation Subcommittee of the American Academy of Neurology. Neurology. 2020;94(9):392-404.

60. Gringras P, Nir T, Breddy J, Frydman-Marom A, Findling RL. Efficacy and safety of pediatric prolonged-release melatonin for insomnia in children with autism spectrum disorder. Journal of the American Academy of Child \& Adolescent Psychiatry. 2017;56(11):948-57. e4.

61. Rubenstein J, Merzenich MM. Model of autism: increased ratio of excitation/inhibition in key neural systems. Genes Brain Behav. 2003;2(5):255-67.

62. Hardan AY, Fung LK, Libove RA, Obukhanych TV, Nair S, Herzenberg LA, et al. A randomized controlled pilot trial of oral $\mathrm{N}$-acetylcysteine in children with autism. Biol Psychiat. 2012;71(11):956-61.

63. Sestili P, Fimognari C. Cytotoxic and antitumor activity of sulforaphane: the role of reactive oxygen species. Biomed Res Int. 2015;2015:402386.

64. Liang J, Hänsch GM, Hübner K, Samstag Y. Sulforaphane as anticancer agent: a double-edged sword? Tricky balance between effects on tumor cells and immune cells. Adv Biol Regul. 2019;71:79-87. 
65. Kamal MM, Akter S, Lin CN, Nazzal S. Sulforaphane as an anticancer molecule: mechanisms of action, synergistic effects, enhancement of drug safety, and delivery systems. Arch Pharm Res. 2020;43(4):371-84.

66. Jardim FR, Almeida FJS, Luckachaki MD, Oliveira MR. Effects of sulforaphane on brain mitochondria: mechanistic view and future directions. J Zhejiang Univ Sci B. 2020;21(4):263-79.

67. Uddin MS, Al Mamun A, Jakaria M, Thangapandiyan S, Ahmad $\mathrm{J}$, Rahman MA, et al. Emerging promise of sulforaphane-mediated Nrf2 signaling cascade against neurological disorders. Science of the Total Environment. 2020;707:135624.

68. Singh K, W Zimmerman A. Sulforaphane treatment of young men with autism spectrum disorder. CNS \& Neurological Disorders-Drug Targets (Formerly Current Drug TargetsCNS \& Neurological Disorders). 2016;15(5):597-601.

69. Singh K, Connors SL, Macklin EA, Smith KD, Fahey JW, Talalay $\mathrm{P}$, et al. Sulforaphane treatment of autism spectrum disorder (ASD). Proc Natl Acad Sci. 2014;111(43):15550-5.

70. Zimmerman AW, Singh K, Connors SL, Liu H, Panjwani AA, Lee L-C, et al. Randomized controlled trial of sulforaphane and metabolite discovery in children with Autism Spectrum Disorder. Molecular autism. 2021;12(1):1-22.

71. Bent S, Bertoglio K, Ashwood P, Bostrom A, Hendren RL. A pilot randomized controlled trial of omega-3 fatty acids for autism spectrum disorder. J Autism Dev Disord. 2011;41(5):545-54.

72. Dolske MC, Spollen J, McKay S, Lancashire E, Tolbert L. A preliminary trial of ascorbic acid as supplemental therapy for autism. Prog Neuropsychopharmacol Biol Psychiatry. 1993;17(5):765-74.

73. Mazahery H, Conlon CA, Beck KL, Mugridge O, Kruger MC, Stonehouse $\mathrm{W}$, et al. A randomised controlled trial of vitamin D and omega-3 long chain polyunsaturated fatty acids in the treatment of irritability and hyperactivity among children with autism spectrum disorder. J Steroid Biochem Mol Biol. 2019;187:9-16.

74. Striepens N, Kendrick KM, Maier W, Hurlemann R. Prosocial effects of oxytocin and clinical evidence for its therapeutic potential. Front Neuroendocrinol. 2011;32(4):426-50.

75. Anagnostou E, Soorya L, Chaplin W, Bartz J, Halpern D, Wasserman S, et al. Intranasal oxytocin versus placebo in the treatment of adults with autism spectrum disorders: a randomized controlled trial. Molecular autism. 2012;3(1):16.

76. Egawa J, Watanabe Y, Shibuya M, Endo T, Sugimoto A, Igeta $\mathrm{H}$, et al. Resequencing and association analysis of OXTR with autism spectrum disorder in a Japanese population. Psychiatry Clin Neurosci. 2015;69(3):131-5.

77. Yamasue H, Okada T, Munesue T, Kuroda M, Fujioka T, Uno Y, et al. Effect of intranasal oxytocin on the core social symptoms of autism spectrum disorder: a randomized clinical trial. Mol Psychiatry. 2020;25(8):1849-58.

78. Bernaerts S, Boets B, Bosmans G, Steyaert J, Alaerts K. Behavioral effects of multiple-dose oxytocin treatment in autism: a randomized, placebo-controlled trial with long-term follow-up. Molecular autism. 2020;11(1):1-14.

79. Mayer AV, Wermter A-K, Stroth S, Alter P, Haberhausen M, Stehr T, et al. Randomized clinical trial shows no substantial modulation of empathy-related neural activation by intranasal oxytocin in autism. Sci Rep. 2021;11(1):1-13.

80. Guastella AJ, Einfeld SL, Gray KM, Rinehart NJ, Tonge BJ, Lambert $\mathrm{TJ}$, et al. Intranasal oxytocin improves emotion recognition for youth with autism spectrum disorders. Biol Psychiat. 2010;67(7):692-4.

81. Yatawara C, Einfeld S, Hickie I, Davenport T, Guastella A. The effect of oxytocin nasal spray on social interaction deficits observed in young children with autism: a randomized clinical crossover trial. Mol Psychiatry. 2016;21(9):1225-31.
82. Parker KJ, Oztan O, Libove RA, Sumiyoshi RD, Jackson LP, Karhson DS, et al. Intranasal oxytocin treatment for social deficits and biomarkers of response in children with autism. Proc Natl Acad Sci. 2017;114(30):8119-24.

83. Anagnostou E, Soorya L, Brian J, Dupuis A, Mankad D, Smile $\mathrm{S}$, et al. Intranasal oxytocin in the treatment of autism spectrum disorders: a review of literature and early safety and efficacy data in youth. Brain Res. 2014;1580:188-98.

84. Dadds MR, MacDonald E, Cauchi A, Williams K, Levy F, Brennan J. Nasal oxytocin for social deficits in childhood autism: a randomized controlled trial. J Autism Dev Disord. 2014;44(3):521-31.

85. Guastella AJ, Gray KM, Rinehart NJ, Alvares GA, Tonge BJ, Hickie IB, et al. The effects of a course of intranasal oxytocin on social behaviors in youth diagnosed with autism spectrum disorders: a randomized controlled trial. J Child Psychol Psychiatry. 2015;56(4):444-52.

86. Sikich L, Kolevzon A, King BH, McDougle CJ, Sanders KB, Kim $\mathrm{S}-\mathrm{J}$, et al. Intranasal oxytocin in children and adolescents with autism spectrum disorder. N Engl J Med. 2021;385(16):1462-73.

87. Gordon I, Jack A, Pretzsch CM, Vander Wyk B, Leckman JF, Feldman R, et al. Intranasal oxytocin enhances connectivity in the neural circuitry supporting social motivation and social perception in children with autism. Sci Rep. 2016;6:35054.

88. Gordon I, Vander Wyk BC, Bennett RH, Cordeaux C, Lucas MV, Eilbott JA, et al. Oxytocin enhances brain function in children with autism. Proc Natl Acad Sci. 2013;110(52):20953-8.

89. Yamasue H, Domes G. Oxytocin and autism spectrum disorders. Behavioral Pharmacology of Neuropeptides: Oxytocin. 2017:449-65.

90. Huang Y, Huang X, Ebstein RP, Yu R. Intranasal oxytocin in the treatment of autism spectrum disorders: a multilevel metaanalysis. Neuroscience \& Biobehavioral Reviews. 2021.

91. Kong X-J, Liu J, Liu K, Koh M, Sherman H, Liu S, et al. Probiotic and oxytocin combination therapy in patients with autism spectrum disorder: a randomized, double-blinded, placebo-controlled pilot trial. Nutrients. 2021;13(5):1552.

92. Spanos M, Chandrasekhar T, Kim S-J, Hamer RM, King BH, McDougle CJ, et al. Rationale, design, and methods of the Autism Centers of Excellence (ACE) network Study of Oxytocin in Autism to improve Reciprocal Social Behaviors (SOARS-B). Contemporary Clinical Trials. 2020;98:106103.

93. Lemonnier E, Ben-Ari Y. The diuretic bumetanide decreases autistic behaviour in five infants treated during 3 months with no side effects. Acta Paediatr. 2010;99(12):1885-8.

94. Lemonnier E, Degrez C, Phelep M, Tyzio R, Josse F, Grandgeorge M, et al. A randomised controlled trial of bumetanide in the treatment of autism in children. Translational psychiatry. 2012;2(12):e202-e.

95. Lemonnier E, Villeneuve N, Sonie S, Serret S, Rosier A, Roue $\mathrm{M}$, et al. Effects of bumetanide on neurobehavioral function in children and adolescents with autism spectrum disorders. Translational psychiatry. 2017;7(3):e1056-e.

96. Fernell E, Gustafsson P, Gillberg C. Bumetanide for autism: openlabel trial in six children. Acta Paediatr. 2021;110(5):1548-53.

97. Sprengers JJ, Van Andel DM, Zuithoff NP, Keijzer-Veen MG, Schulp AJ, Scheepers FE, et al. Bumetanide for core symptoms of autism spectrum disorder (BAMBI): a single center, double-blinded, participantrandomized, placebo-controlled, phase-2 superiority trial. J Am Acad Child Adolesc Psychiatry. 2021;60(7):865-76.

98. Du L, Shan L, Wang B, Li H, Xu Z, Staal WG, et al. A pilot study on the combination of applied behavior analysis and bumetanide treatment for children with autism. J Child Adolesc Psychopharmacol. 2015;25(7):585-8.

99. Crutel V, Lambert E, Penelaud P-F, Albarrán Severo C, Fuentes $\mathrm{J}$, Rosier A, et al. Bumetanide oral liquid formulation for the treatment of children and adolescents with autism spectrum disorder: Design of two phase III studies (SIGN Trials). J Autism Dev Disord. 2021;51(8):2959-72. 
100. Hadjikhani N, Johnels JÅ, Lassalle A, Zürcher NR, Hippolyte L, Gillberg C, et al. Bumetanide for autism: more eye contact, less amygdala activation. Sci Rep. 2018;8(1):1-8.

101. Hadjikhani N, Zürcher NR, Rogier O, Ruest T, Hippolyte L, Ben-Ari $\mathrm{Y}$, et al. Improving emotional face perception in autism with diuretic bumetanide: a proof-of-concept behavioral and functional brain imaging pilot study. Autism. 2015;19(2):149-57.

102. Ben-Ari Y, Lemonnier E. Using bumetanide to treat autism appears promising but further clinical trials are needed to confirm this approach. Wiley Online Library; 2021.

103. James BJ, Gales MA, Gales BJ. Bumetanide for autism spectrum disorder in children: a review of randomized controlled trials. Ann Pharmacother. 2019;53(5):537-44.

104. Fatemi SH, Kneeland RE, Liesch SB, Folsom TD. Fragile X mental retardation protein levels are decreased in major psychiatric disorders. Schizophr Res. 2010;124(1-3):246-7.

105. Fatemi SH, Folsom TD. The role of fragile $X$ mental retardation protein in major mental disorders. Neuropharmacology. 2011;60(7-8):1221-6.

106. Gantois I, Popic J, Khoutorsky A, Sonenberg N. Metformin for treatment of fragile $\mathrm{X}$ syndrome and other neurological disorders. Annu Rev Med. 2019;70:167-81.

107. Monyak RE, Emerson D, Schoenfeld BP, Zheng X, Chambers $\mathrm{DB}$, Rosenfelt $\mathrm{C}$, et al. Insulin signaling misregulation underlies circadian and cognitive deficits in a Drosophila fragile X model. Mol Psychiatry. 2017;22(8):1140-8.

108. Esfahanian N, Shakiba Y, Nikbin B, Soraya H, Maleki-Dizaji N, Ghazi-Khansari M, et al. Effect of metformin on the proliferation, migration, and MMP-2 and-9 expression of human umbilical vein endothelial cells. Mol Med Rep. 2012;5(4):1068-74.

109. Dy ABC, Tassone F, Eldeeb M, Salcedo-Arellano MJ, Tartaglia $\mathrm{N}$, Hagerman R. Metformin as targeted treatment in fragile $\mathrm{X}$ syndrome. Clin Genet. 2018;93(2):216-22.

110. Biag HMB, Potter LA, Wilkins V, Afzal S, Rosvall A, SalcedoArellano MJ, et al. Metformin treatment in young children with fragile X syndrome. Molecular genetics \& genomic medicine. 2019;7(11):e956.

111. Protic D, Kaluzhny P, Tassone F, Hagerman RJ. Prepubertal metformin treatment in fragile $\mathrm{X}$ syndrome alleviated macroorchidism: a case study. Advances in Clinical and Translational Research. 2019;3(1):1-5.

112. Protic D, Aydin EY, Tassone F, Tan MM, Hagerman RJ, Schneider A. Cognitive and behavioral improvement in adults with fragile $\mathrm{X}$ syndrome treated with metformin-two cases. Molecular genetics \& genomic medicine. 2019;7(7):e00745.

113. Osterweil EK, Chuang S-C, Chubykin AA, Sidorov M, Bianchi $\mathrm{R}$, Wong RK, et al. Lovastatin corrects excess protein synthesis and prevents epileptogenesis in a mouse model of fragile $\mathrm{X}$ syndrome. Neuron. 2013;77(2):243-50.

114. Thurman AJ, Potter LA, Kim K, Tassone F, Banasik A, Potter SN, et al. Controlled trial of lovastatin combined with an open-label treatment of a parent-implemented language intervention in youth with fragile X syndrome. J Neurodev Disord. 2020;12(1):1-17.

115. Nelson S, McDuffie A, Banasik A, Feigles RT, Thurman AJ, Abbeduto L. Inferential language use by school-aged boys with fragile X syndrome: effects of a parent-implemented spoken language intervention. J Commun Disord. 2018;72:64-76.

116. Patricio F, Morales-Andrade AA, Patricio-Martínez A, Limón ID. Cannabidiol as a therapeutic target: Evidence of its neuroprotective and neuromodulatory function in parkinson's disease. Frontiers in Pharmacology. 2020;11.

117. Bakas T, Van Nieuwenhuijzen P, Devenish S, McGregor I, Arnold J, Chebib M. The direct actions of cannabidiol and 2-arachidonoyl glycerol at GABAA receptors. Pharmacol Res. 2017;119:358-70.
118. Leweke F, Piomelli D, Pahlisch F, Muhl D, Gerth C, Hoyer C, et al. Cannabidiol enhances anandamide signaling and alleviates psychotic symptoms of schizophrenia. Translational psychiatry. 2012;2(3):e94-e.

119. Russo EB, Burnett A, Hall B, Parker KK. Agonistic properties of cannabidiol at 5-HT1 a receptors. Neurochem Res. 2005;30(8):1037-43.

120. Thiele EA, Marsh ED, French JA, Mazurkiewicz-Beldzinska M, Benbadis SR, Joshi C, et al. Cannabidiol in patients with seizures associated with Lennox-Gastaut syndrome (GWPCARE4): a randomised, double-blind, placebo-controlled phase 3 trial. The Lancet. 2018;391(10125):1085-96.

121. Qin M, Zeidler Z, Moulton K, Krych L, Xia Z, Smith CB. Endocannabinoid-mediated improvement on a test of aversive memory in a mouse model of fragile $\mathrm{X}$ syndrome. Behav Brain Res. 2015;291:164-71.

122. Wei D, Dinh D, Lee D, Li D, Anguren A, Moreno-Sanz G, et al. Enhancement of anandamide-mediated endocannabinoid signaling corrects autism-related social impairment. Cannabis and cannabinoid research. 2016;1(1):81-9.

123. Nezgovorva F. Taylor and Hollander Cannabis, Cannabionids and Immunomodulary agents. Textbook of Autism Spectrum Disorders: Am Psychiatric Assoc Publishing Washington DC; 2022. p. 586-603.

124. Heussler H, Michael Duhig TH, Carol O'Neill, Donna Gutterman, Joseph M. Palumbo, Terri Sebree. Longer term tolerability and efficacy of ZYNO02 cannabidiol transdermal gel in children and adolescents with autism spectrum disorder (ASD): an open label phase 2 study (BRIGHT [ZYN2 CL 030]). Society for Developmental and Behavioral Pediatrics Annual Meeting USA2021.

125. Aran A, Harel M, Cassuto H, Polyansky L, Schnapp A, Wattad $\mathrm{N}$, et al. Cannabinoid treatment for autism: a proof-of-concept randomized trial. Molecular Autism. 2021;12(1):6.

126. Heussler H, Cohen J, Silove N, Tich N, Bonn-Miller MO, Du W, et al. A phase $1 / 2$, open-label assessment of the safety, tolerability, and efficacy of transdermal cannabidiol (ZYNO02) for the treatment of pediatric fragile X syndrome. J Neurodev Disord. 2019;11(1):1-9.

127. Silverman JL, Pride M, Hayes J, Puhger K, Butler-Struben H, Baker $\mathrm{S}$, et al. GABA B receptor agonist R-baclofen reverses social deficits and reduces repetitive behavior in Two mouse models of autism. Neuropsychopharmacology. 2015;40(9):2228-39.

128. Stoppel LJ, Kazdoba TM, Schaffler MD, Preza AR, Heynen A, Crawley JN, et al. R-baclofen reverses cognitive deficits and improves social interactions in two lines of 16p11. 2 deletion mice. Neuropsychopharmacology. 2018;43(3):513-24.

129. Henderson C, Wijetunge L, Kinoshita MN, Shumway M, Hammond RS, Postma FR, et al. Reversal of disease-related pathologies in the fragile $X$ mouse model by selective activation of GABAB receptors with arbaclofen. Science translational medicine. 2012;4(152):152ra28-ra28.

130. Guglielmi L, Servettini I, Caramia M, Catacuzzeno L, Franciolini F, D'Adamo MC, et al. Update on the implication of potassium channels in autism: $\mathrm{K}+$ channelautism spectrum disorder. Front Cell Neurosci. 2015;9:34

131. Berry-Kravis EM, Hessl D, Rathmell B, Zarevics P, Cherubini M, Walton-Bowen K, et al. Effects of STX209 (arbaclofen) on neurobehavioral function in children and adults with fragile $\mathrm{X}$ syndrome: a randomized, controlled, phase 2 trial. Science translational medicine. 2012;4(152):152ra27-ra27.

132. Berry-Kravis E, Hagerman R, Visootsak J, Budimirovic D, Kaufmann WE, Cherubini M, et al. Arbaclofen in fragile X syndrome: results of phase 3 trials. J Neurodev Disord. 2017;9(1):1-18.

133. Tropea D, Giacometti E, Wilson NR, Beard C, McCurry C, Fu DD, et al. Partial reversal of Rett Syndrome-like symptoms in MeCP2 mutant mice. Proc Natl Acad Sci. 2009;106(6):2029-34. 
134. Shcheglovitov A, Shcheglovitova O, Yazawa M, Portmann T, Shu $\mathrm{R}$, Sebastiano V, et al. SHANK3 and IGF1 restore synaptic deficits in neurons from $22 \mathrm{q} 13$ deletion syndrome patients. Nature. 2013;503(7475):267-71.

135. Linker SB, Mendes AP, Marchetto MC. IGF-1 treatment causes unique transcriptional response in neurons from individuals with idiopathic autism. Molecular Autism. 2020;11(1):1-13.

136. Bozdagi $\mathrm{O}$, Tavassoli $\mathrm{T}$, Buxbaum JD. Insulin-like growth factor-1 rescues synaptic and motor deficits in a mouse model of autism and developmental delay. Molecular autism. 2013;4(1):1-4.

137. Glaze DG, Neul JL, Kaufmann WE, Berry-Kravis E, Condon S, Stoms G, et al. Double-blind, randomized, placebo-controlled study of trofinetide in pediatric Rett syndrome. Neurology. 2019;92(16): e1912-25.

138. Berry-Kravis E, Horrigan JP, Tartaglia N, Hagerman R, Kolevzon A, Erickson CA, et al. A double-blind, randomized, placebo-controlled clinical study of trofinetide in the treatment of fragile $\mathrm{X}$ syndrome. Pediatr Neurol. 2020;110:30-41.

139. Deacon RM, Glass L, Snape M, Hurley MJ, Altimiras FJ, Biekofsky RR, et al. NNZ-2566, a novel analog of (1-3) IGF-1, as a potential therapeutic agent for fragile $\mathrm{X}$ syndrome. NeuroMol Med. 2015;17(1):71-82.

140. Berry-Kravis E, Huttenlocher PR. Cyclic AMP metabolism in fragile X syndrome. Annals of Neurology: Official Journal of the American Neurological Association and the Child Neurology Society. 1992;31(1):22-6.

141. Choi CH, Schoenfeld BP, Bell AJ, Hinchey J, Rosenfelt C, Gertner MJ, et al. Multiple drug treatments that increase cAMP signaling restore long-term memory and aberrant signaling in fragile $\mathrm{X}$ syndrome models. Front Behav Neurosci. 2016;10:136.

142. Gurney ME, Cogram P, Deacon RM, Rex C, Tranfaglia M. Multiple behavior phenotypes of the fragile-X syndrome mouse model respond to chronic inhibition of phosphodiesterase-4D (PDE4D). Sci Rep. 2017;7(1):1-11.

143. Berry-Kravis EM, Harnett MD, Reines SA, Reese MA, Ethridge LE, Outterson AH, et al. Inhibition of phosphodiesterase-4D in adults with fragile $\mathrm{X}$ syndrome: a randomized, placebo-controlled, phase 2 clinical trial. Nat Med. 2021;27(5):862-70.
144. Reyes ST, Deacon RM, Guo SG, Altimiras FJ, Castillo JB, van der Wildt B, et al. Effects of the sigma-1 receptor agonist blarcamesine in a murine model of fragile $\mathrm{X}$ syndrome: neurobehavioral phenotypes and receptor occupancy. Sci Rep. 2021;11(1):1-14.

145. Kaufmann WE, Sprouse J, Rebowe N, Hanania T, Klamer D, Missling CU. ANAVEX ${ }^{\circledR}$ 2-73 (blarcamesine), a Sigma-1 receptor agonist, ameliorates neurologic impairments in a mouse model of Rett syndrome. Pharmacology Biochemistry and Behavior. 2019;187:172796.

146. Hampel H, Williams C, Etcheto A, Goodsaid F, Parmentier F, Sallantin J, et al. A precision medicine framework using artificial intelligence for the identification and confirmation of genomic biomarkers of response to an Alzheimer's disease therapy: analysis of the blarcamesine (ANAVEX2-73) Phase 2a clinical study. Alzheimer's \& Dementia: Translational Research \& Clinical Interventions. 2020;6(1):e12013.

147. Macfarlane S, Maruff P, Cecchi M, Moore D, Zografidis T, Missling C. P1-046: New exploratory Alzheimer'sdDrug Anavex 2-73: dose dependent clinical cognitive improvement observed in mini mental state examination (MMSE) and other cognitive markers in a phase 2A study in mild-to-moderate Alzheimer's patients. Alzheimer's \& Dementia. 2016;12:P419-P.

148. Christ MG, Clement AM, Behl C. The sigma-1 receptor at the crossroad of proteostasis, neurodegeneration, and autophagy. Trends Neurosci. 2020;43(2):79-81.

149. Hagerman R, Hagerman P. Fragile X-associated tremor/ataxia syndrome: Pathophysiology and management. Curr Opin Neurol. 2021;34(4):541-6.

150. Frye RE, editor Mitochondrial dysfunction in autism spectrum disorder: Unique abnormalities and targeted treatments. Seminars in pediatric neurology; 2020: Elsevier.

Publisher's Note Springer Nature remains neutral with regard to jurisdictional claims in published maps and institutional affiliations. 